\title{
A Review of Critical Mathematics Education: Theory, Praxis, and Reality
}

\author{
Jeremy Sundeen
}

\section{University of Regina}

Critical Mathematics Education: Theory, Praxis, and Reality is a collection of 17 chapters written by a number of authors and edited by Paul Ernest, Bharatha Sriraman and Nuala Ernest. In their forward, the Editors summarize three major recurring themes throughout the book Chapters: (a) the epistemological roots of mathematics and critical mathematics, (b) the hegemony of mathematics in society, and (c) mathematics and its ties to capitalism, globalization, and politics. This book serves as a significant contribution to theoretical knowledge in critical mathematics and also provides practical applications from the theoretical for practising educators. This book review is written from two perspectives: a (becoming) critical mathematics education researcher, and a practising secondary mathematics teacher.

\section{A (Becoming) Critical Mathematics Education Researcher}

From the perspective of a graduate student (at the University of Regina, Saskatchewan, Canada), about to begin research for a thesis on critical mathematics education, this book serves as a valuable resource and starting place for research. While the book begins by looking at critical mathematics from a theoretical perspective, it continually seeks to create connections between theory and practice. This book includes notable critical mathematics authors such as Ole Skovsmose, Ubiratan D’Ambrosio and Paul Ernest, not to mention numerous other well-known scholars in the field. With such notable scholars, the book possesses a certain level of authority in the field and one that is beneficial for new researchers (like myself).

In the book, various perspectives are presented, which describe, analyze, and theorize critical mathematics and critical mathematics education. Many authors draw on their own empirical research studies, which inform their book chapter. Other chapters are theoretical in nature, often explaining the historical roots of different terms associated with critical mathematics: ethnomathematics (Francois, Chapter 10), democracy in mathematics (Corlu, Chapter 16) and real-life mathematics (Alro \& Johnsen-Hoines, Chapter 12). Yasukawa, Skovsmose and Ravn present new theoretical frameworks to frame their research (Chapter 4); while others build on notable sociological researchers such as Bourdieu (Wedege, Chapter 7; Jorgensen (Zevenbergen), Chapter 6) and Foucault (Giongo \& Knijnik, Chapter 9), incorporating those theoretical perspectives into critical mathematics education. This book provides both theoretical and practical chapters from a variety of authors showing the current scope of critical mathematics research.

In this review, I will outline a few examples where authors establish a need for critical mathematics. In Chapter 3, Paul Ernest takes a critical perspective on academia where mathematics research can be viewed as a knowledge economy, one that is exploitative through a brain drain on developing countries. Ole Skovsmose (Chapter 1) discusses mathematical modelling in the airline industry, where flights are overbooked based on a probability model that some passengers will miss a flight; these passengers are bumped from a flight when they arrive, even though they paid full fare. These two examples establish a need for a critical perspective in mathematics and how mathematics is used in society. In other words, mathematics can be viewed as a tool that can be used for the exploitation of knowledge (Ernest, Chapter 3) or to maximize 
profits at all costs (Skovsmose, Chapter 1); here we see the intersection of globalization, capitalism, and the use of mathematics that creates inequality.

A central theme in the book is that the discipline of mathematics is not value-free (Skovsmose, Chapter 1; D’Ambrosio, Chapter 2; Ernest, Chapter 3). Mathematics has multiple uses: as a language, a school subject, research area, engineering tool, game, and multiple other uses. Sometimes mathematics can be applied and other times it can claim to be pure (Yasukawa, Skovsmose \& Ravn, Chapter 4). Mathematics is often understood using multiple perspectives and, according to Yasukawa, Skovsmose and Ravn, the lens chosen to view mathematics determines what is observed; therefore, there exists a need to analyze "mathematics in action" (Yasukawa, Skovsmose, \& Ravn, p. 82). Their chapter presents their theoretical perspective where mathematics can be viewed as an action entering an ethical domain through "description, inscription, prescription and subscription" (p. 96). That is, viewing "mathematics in action" creates an ethical domain where the authors critique not just the philosophy of mathematics but also technology and social theorizing in general.

This book does a good job of interrogating the epistemological roots of mathematics, why and how mathematics has become a dominant knowledge system, and how mathematics is used to permeate capitalist global values to benefit those in places of authority (Nikolakaki, Chapter 14). After reading the book as a new researcher, I begin to see the global landscape in critical mathematics education and the importance of choosing wisely in terms of where my research is published, whose interests my publications serve, and how I must be reflexive in all aspects of my research.

The book establishes a need to further investigate, question and critique dominant ideologies using anthropological, psychological, and sociological theories. However, Ernest warns that a critical mathematics researcher must also be keenly aware how "we enjoy theorizing from our ivory towers, but rarely get our hands dirty on the frontlines of social struggle, or even at the chalkface” (Ernest, Chapter 3, p. 119). Ernest reminds critical researchers that there should be a practical aspect to critical mathematics research.

\section{A Practising Secondary Mathematics Teacher}

For me as a practising secondary mathematics teacher, the book illustrates how mathematics education is deeply rooted in a colonial past where lower socioeconomic class students are taught the mathematical skills they need to assume their role in society (Ernest, Chapter 2; Jorgensen (Zevenbergen), Chapter 6; Greer \& Mukhopadhyay, Chapter 8). There is an illusion that mathematics education creates equal opportunity for all citizens but numerous authors in this book articulate that mathematics education can be used as a tool to sort, classify and assign social and cultural capital (Wedege, Chapter 7; Ernest, Chapter 5; D’Ambrosio, Chapter 3). Many authors provide examples for educators to use in their classrooms that are rooted in critical mathematics theories. These empirical studies connect the theoretical aspects of critical mathematics education to a practical side, providing extreme value for teachers looking to apply theory to practice. In his chapter, Paul Ernest (Chapter 5) pushes critical mathematics education to the limit by suggesting that critical pedagogy is not enough; simply adopting a critical pedagogy is insufficient. Ernest goes on to suggest adopting critical pedagogy alone may build complacency from a place of self-admiration. Critical mathematics educators must adopt critical 
pedagogy and make theoretical connections in their classrooms in order to develop critical consciousness and social agency. Below are a few examples of such real-world extensions.

Annica Andersson and Paola Valero (Chapter 11) write about a doctoral student and a mathematics teacher who integrate social issues into their mathematics classrooms. One of their most powerful examples was a statistics project where students explored (and calculated) their ecological footprint. The project took 3 weeks to complete but the mathematics and social awareness created, according to the authors, was remarkable. Dennis Almeida (Chapter 15) provides tasks that connect critical thinking and mathematical proof. Almeida allows his students to explore a variety of different approaches to proof and he writes that, when teaching mathematics, there is "little room for transmission mode teaching which suggests to pupils that mathematics is abstract, rule ridden and without explanation, value and culture free" (p. 306). There seems to be a pedagogical connection, but not limited to a pedagogical approach, for critical mathematics educators, which has little space for direct instruction.

Overall, the book proposes that creating opportunities to explore social issues in mathematics classrooms are vital for students to recognize their agency in the wake of globalization. One of the overarching goals of critical mathematics education is to give students the ability to recognize mathematics and how it is used in society. A part of this approach includes a critique of mathematics and how it is used in social, economic, and political aspects of society. According to Nikolakaki (Chapter 14), one of the largest oppressive powers facing global inequality is the oppression created by corporations in the global market place. Critical mathematics educators must give students the ability to recognize and analyze such situations to create “society’s conscientization” (Nikolakaki, p. 285).

The reality of the world is that injustices exist. I think Ubiratan D’Ambrosio (Chapter 2) states it best:

Mathematics is the most universal mode of thought and that survival with dignity is the most universal problem facing mankind... [i]t is absolutely natural to expect that mathematicians and math educators look into the relations between these two universals, that is, into the role of mathematicians and math educators in the pursuit of a civilization with dignity for all, in which inequity, arrogance, and bigotry have no place. (p. 24-25)

Mathematics can be viewed from multiple perspectives and this book establishes a need to do so from a critical perspective because mathematics is not values-free. This book serves as a significant contribution to research in the field of critical mathematics education, going beyond theory in critical mathematics education by connecting to the practical, and in this way establishing praxis towards global justice.

\section{Reference}

Ernest, P., Sriraman, B., \& Ernest, N. (Eds). (2016). Critical mathematics education: Theory, praxis, and reality. Charlotte, NC: Information Age. 